\title{
Gas probes and their application in gas therapy
}

\author{
Wan-Jun Gong ${ }^{1,2}$, Zhi-Qiang Yü ${ }^{3}$, Qian-Jun $\mathrm{He}^{1,4^{*}}$ \\ ${ }^{1}$ School of Biomedical Engineering, Health Science Center, Shenzhen University, Shenzhen 518060, Guangdong, China. \\ ${ }^{2}$ Department of Pharmacy, Shenzhen Hospital, Southern Medical University, Shenzhen 518052, Guangdong, China. \\ ${ }^{3}$ Guangdong Provincial Key Laboratory of New Drug Screening, School of Pharmaceutical Sciences, Southern Medical University, \\ Guangzhou 510515, Guangdong, China. \\ ${ }^{4}$ Center of Hydrogen Science, Shanghai Jiao Tong University, Shanghai 200240, China.
}

${ }^{\star}$ Correspondence to: Prof. Qian-Jun He, School of Biomedical Engineering, Health Science Center, Shenzhen University, 1066 Xueyuan road, Nanshan District, Shenzhen 518060, Guangdong, China. E-mail: nanoflower@126.com

How to cite this article: Gong WJ, Yu ZQ, He QJ. Gas probes and their application in gas therapy. Chem Synth 2021;1:3. https://dx.doi.org/10.20517/cs.2021.04

Received: 8 Jun 2021 First Decision: 28 Jun 2021 Revised: 1 Jul 2021 Accepted: 5 Jul 2021 First online: 6 Jul 2021

Academic Editor: Bao-Lian Su Copy Editor: Yue-Yue Zhang Production Editor: Yue-Yue Zhang

\begin{abstract}
As an emerging field, gas therapy attracts increasing attention because of its distinguishing features in disease treatment. However, to achieve a therapeutic effect, the concentration of gas should be carefully controlled. Thus, a suitable and convenient technology is required to monitor the gas concentration in vivo. Besides, the transportation of gas into human body and in vivo biodistribution of gas also need to be evaluated. Among the technologies adopted in gas therapy, fluorescence imaging technology is the first choice due to its high specificity, high sensitivity, and non-invasion. And as the core of fluorescence imaging, the properties of fluorescent dyes directly determine the quality of imaging. So, it is critical to choose suitable gas probes for different purposes. Here, we review common gas detection methods, including a brief introduction of fluorescence, the distinctive properties of five fluorophore cores, and the detection mechanisms of common gas probes. Then, the applications of gas probes in gas delivery, gas release, and gas therapy are summarized. At last, we discuss the potential of developing further intelligent gas probes and fluorescence imaging technologies for gas therapy.
\end{abstract}

Keywords: Gas therapy, fluorescence imaging, bioprobe, gas detection, gas delivery

\section{INTRODUCTION}

In the past decades, there are several small gas molecules, including NO (nitric oxide), CO (carbon monoxide), $\mathrm{CO}_{2}$ (carbon dioxide), $\mathrm{H}_{2} \mathrm{~S}$ (hydrogen sulfide), $\mathrm{O}_{2}$ (oxygen), $\mathrm{NO}_{2}$ (nitrogen dioxide), and $\mathrm{H}_{2}$ 
(hydrogen), which can exhibit biological effects in the human body. NO, for example, has been regarded as a serious air pollutant and poisonous to human health for a long time. But a more comprehensive understanding of $\mathrm{NO}$ was achieved when $\mathrm{NO}$ was uncovered to be a signal molecule generated by endothelial cells in the presence of acetylcholine responsible for the relaxation effect. Along with relaxation function, $\mathrm{NO}$ also regulates cellular processes, such as angiogenesis, immune response, apoptosis, and synaptic communication. Moreover, NO radical has been proven to be involved in the etiology and progression of many diseases including various cancers.

In contrast to compounds of structural complexity, gas molecules are easier to obtain and more stable under physical conditions. In addition, their transport into the human body could be achieved through several means such as direct inhalation or consumption of gas-rich water. Due to these advantages, the newly burgeoning field of gas therapy has emerged. Gas therapy has distinct advantages over pharmaceutical drugs. First, gas molecules are extremely small so that they can easily cross biomembranes and diffuse into varied subcellular organelles. With these advantages, the gases may be effective in treating clinically many diseases. Moreover, gas molecules such as hydrogen are much safer biologically and have fewer toxic side effects than traditional drugs, and multidrug resistance could be overcome to a certain extent when gases are integrated with drugs.

Only at the right location and proper concentration, therapeutic gases can perform their therapeutic effects and biological roles. Thus, it is of significant importance to monitor the biodistribution and concentration of therapeutic gases during treatment. As having been developed for years, imaging systems like CT (computed tomography) in clinical research could allow us to get the details of attractive targets. However, in regard to small molecules, particularly for in vivo imaging, fluorescence imaging is frequently the first choice. With a suitable fluorescent probe, a fluorescence microscope could provide the detailed structure of an interesting target, and because of non-invasiveness, fluorescence imaging has become one of the most popular methods to study the dynamic behavior of drugs in live cells and animal models. Recently, nearinfrared (NIR) fluorophores have greatly improved imaging quality in deep-tissue imaging. Combined with the importance of gas therapy, a big challenge in achieving in vivo gas monitoring is to design appropriate fluorescent probes. Thus, we here provide a review concentrated on the fluorophores used in gas therapy involving their fluorescent properties, their mechanisms of turn-on or turn-off when reacting with therapeutic gases, and their applications in gas therapy.

\section{FLUORESCENT PROBES FOR GAS DETECTION}

As illustrated by the Jablonski diagram in Figure $1 \mathrm{~A}$, a molecule in the $\mathrm{S}_{0}$ state could absorb certain energy to jump up to the $S_{1}$ stage, then returns to the $S_{0}$ stage by emitting a photon normally. These molecules could be termed fluorophores, and this phenomenon is fluorescence. The fluorescence was discovered for the first time in 1845 by Fredrick W. Herschel when a quinine solution was illuminated by a UV light and blue light was observed. Following this, the growing fluorescence foundation was reported and numerous fluorophores were discovered or synthesized. Fluorophores typically refer to small organic molecules (20100 atoms) which are most widely used and explored. However, fluorescent proteins such as green fluorescent protein and fluorescent particles such as quantum dots widen the fluorophore family. But as a kind of specific probe or sensor, organic fluorophores are often the first choice because of their broad spectral range, small size, high photostability, and high brightness.

After decades of development, many organic fluorophores with excellent photophysical properties have been designed and synthesized. These organic fluorescent molecules have not only enriched the family of fluorescent dyes but also help researchers to solve a wide range of problems. Though the structures of 


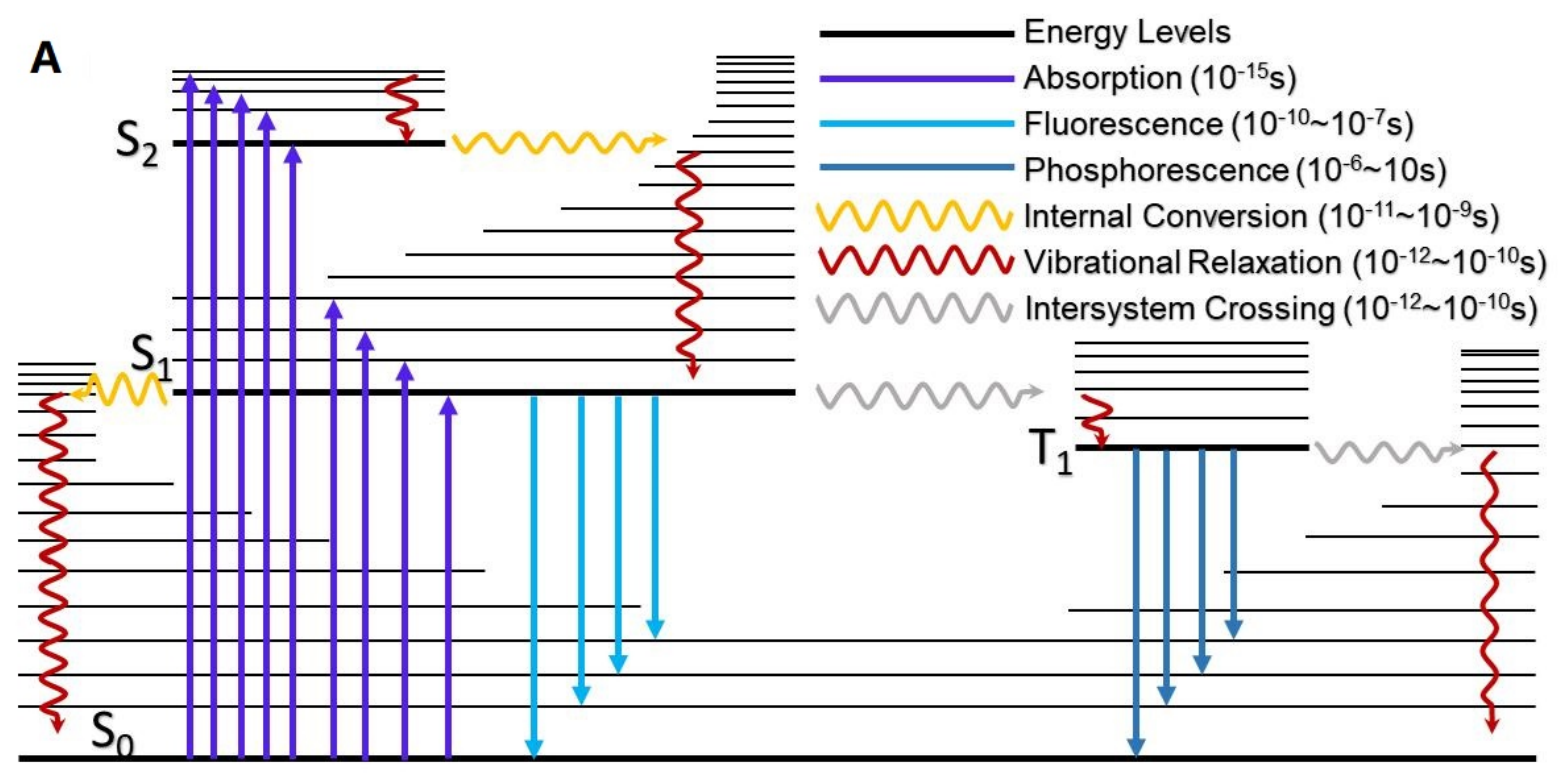

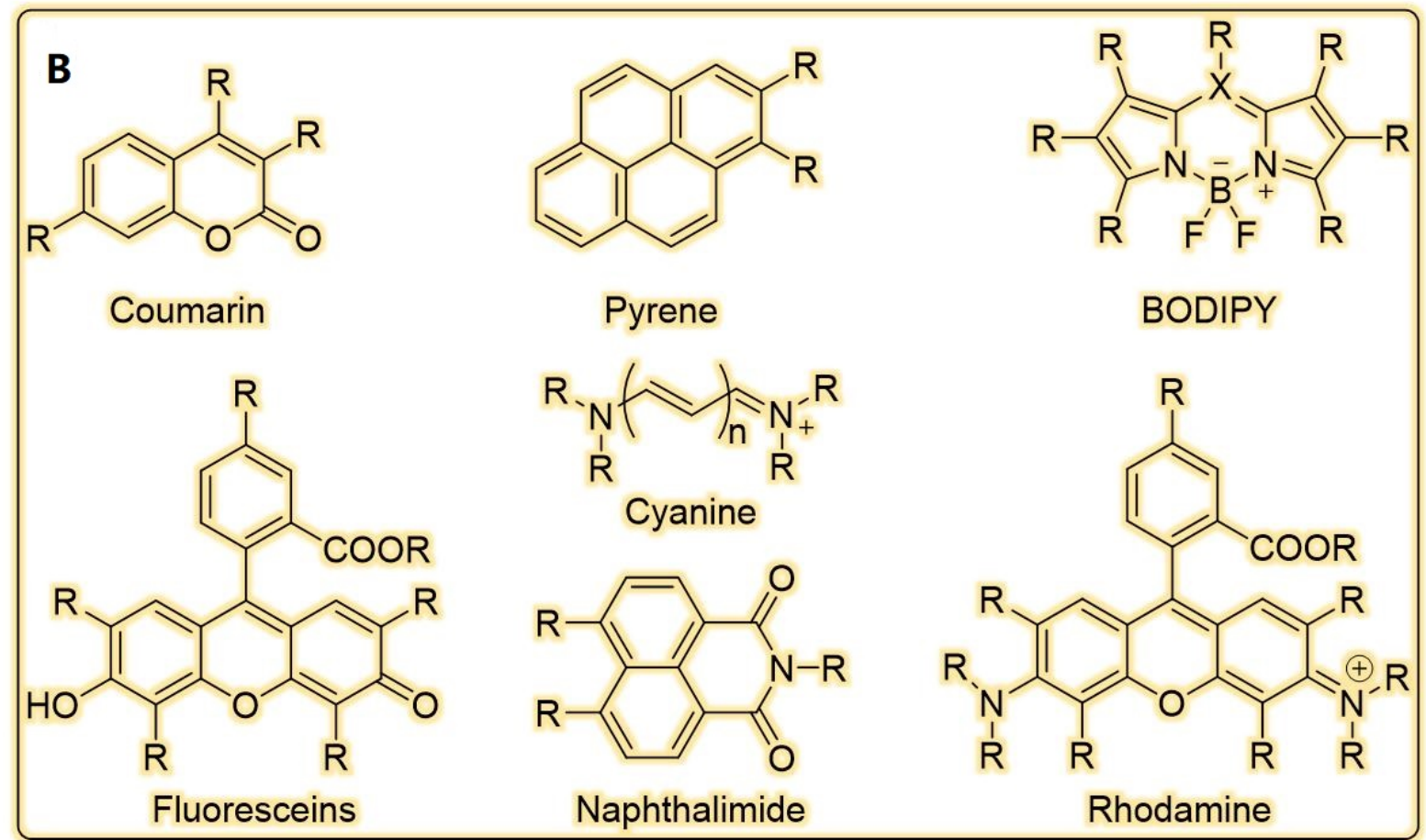

Figure 1. Jablonski diagram (A) and several commonly used fluorophore cores (B).

fluorescent molecules vary, the core structure that is responsible for absorbing and emitting light remains the same. Generally, synthesized organic dyes are based on several basic structures, such as coumarin, 1,8naphthalimide, BODIPY (boron-dipyrromethene), xanthene, pyrene, and cyanine [Figure 1B]. These basic structures own their distinct advantages. For example, regarding fluorophores based on xanthene, including fluoresceins and rhodamines, their high photostability and high fluorescence quantum yields make them suitable for long-duration imaging. And the absorbance and emission wavelength could be adjusted by modifying their structures to extend their applications. But due to the existence of hydroxyl and amine 
groups, most of them are sensitive to $\mathrm{pH}$. So, environmental acidity must therefore be taken into consideration when they are used for molecular recognition. But this problem does not exist in most BODIPY-based probes. In this section, we summarized a variety of gas probes based on different fluorophore cores including their structural characteristics [Figure 2], photophysical properties [Table 1], and gas detection mechanisms.

\section{Coumarin-based gas probes}

Coumarin compounds are a class of important heterocyclic chemicals that widely exist in nature, and the coumarin core itself owns excellent optical properties. Moreover, the introduction of an electron acceptor group in the $3 / 4$ position and an electron donor group in the 6/7 position could form a pull-push electron system, leading to an increase of fluorescence quantum yield. And this pull-push electron system could be further modified to control fluorescence behaviors. Taking advantage of easy modification, high fluorescence quantum yield, large Stokes' shift, good stability, and high cell penetration ability, coumarin derivatives are utilized for ion and small molecule detection. And in the field of gas molecule recognition, coumarin-based probes are typically used for intracellular detection of $\mathrm{H}_{2} \mathrm{~S}$ and $\mathrm{SO}_{2}$.

The coumarin core structure is rigid and stable, and hard to be chemically attacked. But a $\pi$-conjunction system with expanding modification could not only change its photophysical properties but also give rise to chemical reactivity. For instance, inspired by salicylaldehyde, the aldehyde group on coumarin was found to be reactive ${ }^{[1-3]}$, and this structure could be used for $\mathrm{SO}_{2}$ detection. Another way to endow coumarin with gas detection performance is also to introduce unsaturated bonds $s^{[4-7]}$. The conjugated system would be broken if these bonds reacted with analytes, and the fluorescence signal changed consequently [Figure $3 \mathrm{~A}$ ]. Coumarin-based fluorescent probes are also useful for sensing $\mathrm{H}_{2} \mathrm{~S}$. Hatai et al. ${ }^{[8]}$ prepared coumarin-based spherical nanoparticles, in which the fluorescence was quenched by $\mathrm{Pd}^{2+}$. And after reacting with $\mathrm{H}_{2} \mathrm{~S}$, the polymer decomposed and fluorescence recovered. Another strategy used for detecting $\mathrm{H}_{2} \mathrm{~S}$ is the reducing reaction of $\mathrm{NO}_{2}$ into $\mathrm{NH}_{2}^{[2]}$. Once the reaction was triggered by $\mathrm{H}_{2} \mathrm{~S}$, coumarin analogues would shed high fluorescence because of the distinction of electronegativity between azido and amino groups.

After a credible method for gas detection was established, fluorescent probes began to be used for varied purposes in gas therapy. Shen et al..$^{[9]}$ designed and synthesized a kind of glutathione (GSH)-responsive polymer prodrug of $\mathrm{SO}_{2}$. To investigate intracellular release of $\mathrm{SO}_{2}$ triggered by thiol, DEACA was adopted as a fluorescent probe, and after reacting with released $\mathrm{SO}_{2}$, fluorescence intensity of the probe increased by three folds [Figure 4A]. Li et al ${ }^{[10]}$ also used DEACA to study the photo-induced release of $\mathrm{SO}_{2}$ from NIRsensitive nanoparticles. By comparing the fluorescence change at $483 \mathrm{~nm}$ of different samples, they proved that $\mathrm{SO}_{2}$ was controllably produced by applying $980 \mathrm{~nm}$ laser stimuli.

\section{BODIPY-based gas probes}

BODIPY dyes are a widely used fluorophore family because their core is highly tolerant to substitutions for varied applications, and a small addition to the core structure could cause a change in fluorescence properties. In addition to this advantage, BODIPY-based fluorophores generally have a high molar extinction coefficient and high fluorescence quantum yield, and these properties are solvent-independent. Otherwise, the small FWHM (full width at half maximum) of emission spectra benefits them in the collection of fluorescence signals to avoid the interruption of other fluorescent materials. Moreover, BODIPY-based fluorophores commonly have high photostability, making them suitable for long-time observation applications. Owing to these excellent properties, BODIPY-based fluorophores have been widely utilized in various fields. 
Table 1. Probes for gas detection and its basic photophysical properties

\begin{tabular}{|c|c|c|c|c|}
\hline Probe & Excitation $(\mathrm{nm})$ & Detection (nm) & Gas & Ref. \\
\hline Naphthalene & 282 & 336 & $\mathrm{CO}_{2}$ & [38] \\
\hline Pyrene & 341 & 380 & $\mathrm{CO}_{2}$ & [38] \\
\hline Coumarin-Pd & 310 & 390 & $\mathrm{H}_{2} \mathrm{~S}$ & {$[8]$} \\
\hline Courmarin- $\mathrm{H}_{2} \mathrm{~S}-1$ & 400 & 450 & $\mathrm{SO}_{2}$ & [1] \\
\hline Courmarin- $\mathrm{H}_{2} \mathrm{~S}-2$ & 390 & 483 & $\mathrm{H}_{2} \mathrm{~S}$ & {$[2]$} \\
\hline DAF & 490 & 500 & NO & [25] \\
\hline DAMBOs & 490 & 507 & NO & [16] \\
\hline COP-1 & 475 & 507 & $\mathrm{CO}$ & [11] \\
\hline SFP-2 & 465 & 510 & $\mathrm{H}_{2} \mathrm{~S}$ & [18] \\
\hline HPTS & 470 & 515 & $\mathrm{CO}_{2}$ & [39] \\
\hline Fluoresceins- $\mathrm{H}_{2} \mathrm{~S}-2$ & 455 & 517 & $\mathrm{H}_{2} \mathrm{~S}$ & [23] \\
\hline Diaminofluoresceins & 490 & 520 & NO & [24] \\
\hline Fluoresceins- $\mathrm{H}_{2} \mathrm{~S}-1$ & 465 & 520 & $\mathrm{H}_{2} \mathrm{~S}$ & [30] \\
\hline FL-CO-1 & 490 & 520 & $\mathrm{CO}$ & [31] \\
\hline BODIPY- $\mathrm{N}_{3}$ & 495 & 520 & $\mathrm{H}_{2} \mathrm{~S}$ & [17] \\
\hline BODIPY-cobaloxime & 490 & 520 & $\mathrm{H}_{2} \mathrm{~S}$ & [14] \\
\hline Ozone probe-1 & 497 & 523 & $\mathrm{O}_{3}$ & [28] \\
\hline Coumarin-NIR-1 & 466 & 523 & $\mathrm{SO}_{2}$ & {$[5]$} \\
\hline FL-CO-New & 490 & 527 & $\mathrm{CO}$ & [32] \\
\hline Lyso-NINO & 440 & 530 & NO & [37] \\
\hline HSN & 435 & 540 & $\mathrm{H}_{2} \mathrm{~S}$ & [36] \\
\hline Bis-pyrene & 500 & 550 & $\mathrm{CO}_{2}$ & [40] \\
\hline Rhodamine-NO-2 & 540 & 570 & NO & [22] \\
\hline DARs & 540 & 570 & NO & [27] \\
\hline Resorufin Levulinate-1 & $\sim 487$ & 588 & $\mathrm{H}_{2} \mathrm{~S}$ & [29] \\
\hline Rhodamine-NO-1 & 570 & 616 & NO & [26] \\
\hline $\mathrm{HS}-\mathrm{CY}$ & 510 and 700 & $625(510) / 780(700)$ & $\mathrm{H}_{2} \mathrm{~S}$ & [33] \\
\hline BODIPY-Le & 538 & $647 / 570$ & $\mathrm{H}_{2} \mathrm{~S}$ & [15] \\
\hline Coumarin-NIR-2 & 580 & 663 & $\mathrm{SO}_{2}$ & [5] \\
\hline $\mathrm{Cy}-\mathrm{N}_{3}$ & 625 & $750 / 710$ & $\mathrm{H}_{2} \mathrm{~S}$ & [34] \\
\hline $\mathrm{BF}_{2}$ chelate & 610 & 913 & $\mathrm{CO}_{2}$ & [19] \\
\hline
\end{tabular}

As the structure illustrates, BODIPY fluorophores own up to seven sites to modify. As a result, their fluorescence could be quenched by several methods. So, different gas detection strategies have been designed based on the cleavage of quenching fraction. For example, as known to all, heavy metals could efficiently quench fluorescence. So, a palladium-mediated carbonylation reactivity-based CO probe (COP-1) was reported by Michel ${ }^{[11]}$. The fluorophore of the probe was based on BODIPY whose fluorescence was quenched by the Pd atom via heavy-atom electronic effect. Upon reacting with $\mathrm{CO}$, Pd was released and its fluorescence recovered [Figure 3D]. Using this method, the as-prepared probe could selectively react with $\mathrm{CO}$ over a variety of reactive nitrogen, oxygen, and sulfur species and can be used to image $\mathrm{CO}$ in living cells $s^{[12,13]}$. A similar strategy was also used for the detection of $\mathrm{H}_{2} \mathrm{~S}$ in the presence of $\mathrm{CO}^{[14]}$. Others quenching methods involves levulinate ${ }^{[15]}$ and aromatic diamine $\mathrm{e}^{[16]}$ which are easily and selectively reacted with sulfite ${ }^{[15]}$ and $\mathrm{NO}^{[16]}$, respectively.

Besides the quenching moiety, the photophysical property of fluorophore could also be regulated by other methods. In some cases, reaction or environment change could interrupt the photo-induced electron transfer or the intramolecular electron transfer ${ }^{[17]}$. For example, when the adjacent hydrogen atoms in an 


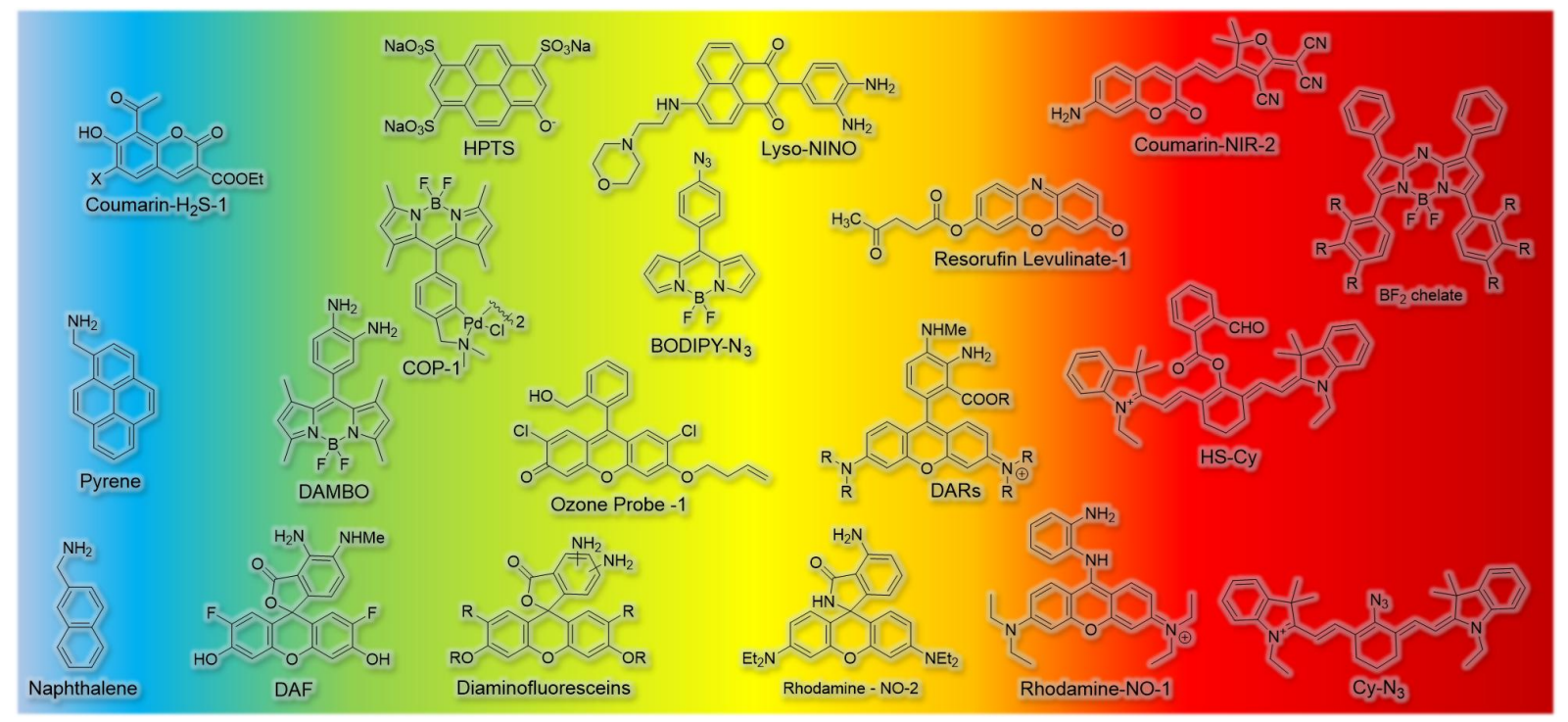

Figure 2. Typical fluorescent probes for detection of varied gas molecules.

aromatic structure are replaced by aldehyde and $\alpha, \beta$-unsaturated moiety, the $\mathrm{CHO}$ group is ready to react with free sulfide and the formed intermediate could further react with the unsaturated bond by the Michael addition to generate a thioacetal. Based on the tandem reaction, a BODIPY-based $\mathrm{H}_{2} \mathrm{~S}$ probe was synthesized by Qian et al. ${ }^{[18]}$ and used to monitor enzymatic $\mathrm{H}_{2} \mathrm{~S}$ biogenesis and image-free sulphide in living cells.

It is common sense that the environmental $\mathrm{pH}$ value should be taken into consideration in probe design because photophysical properties are easily influenced by the $\mathrm{pH}$ change, especially when the probes contain $\mathrm{pH}$-sensitive groups. But on the other hand, these kind of probes could be utilized since the dissolving process of $\mathrm{CO}_{2}$ is usually accompanied by $\mathrm{pH}$ change. Based on this strategy, Schuttting et al. ${ }^{[19]}$ synthesized a set of BODIPY-based NIR molecules with hydroxyl groups for $\mathrm{CO}_{2}$ detection.

\section{Xanthene-based gas probes}

Xanthene fluorescent dyes are mainly divided into two types according to the substituents on the 3 and 6 sites, which were substituted by amino and hydroxyl compounds for construction of rhodamine ${ }^{[20]}$ and fluorescein ${ }^{[21]}$, respectively. With similar structures, the two types shared the similar features such as good photo-resistance, high absorption coefficient, high fluorescence quantum yield, and relatively long emission wavelength. But due to the distinctive properties of nitrogen and oxygen atoms, rhodamine commonly owns higher emission intensity and more modification sites than fluoresceins. However, compared to rhodamine, fluorescein derivatives always are more water-soluble.

There are three typical principles for designing fluorescent probes based on rhodamine and fluorescein. First, it should be noticed that carboxylic and hydroxyl groups in the structure could react with the double bond to yield spirocyclic derivatives. As a result, the fluorescence turns off once the conjunction system of xanthene was broken [Figure $3 \mathrm{C}$ ]. Based on this strategy, a NO fluorescent probe was designed and synthesized by Zheng et al. ${ }^{[2]}$; Rhodamine NO-2 consisted of two parts, rhodamine B spirolactam and ophenylenediamine. The spiro ring of rhodamine would open while amino group was diazotized and then the intermediates hydrolyzed into rhodamine $\mathrm{B}$ and benzotriazole with fluorescence enhancement. Using a similar strategy, another fluorescent probe based on fluorescein (Fluorescein- $\mathrm{H}_{2} \mathrm{~S}-2$ ) was reported by 


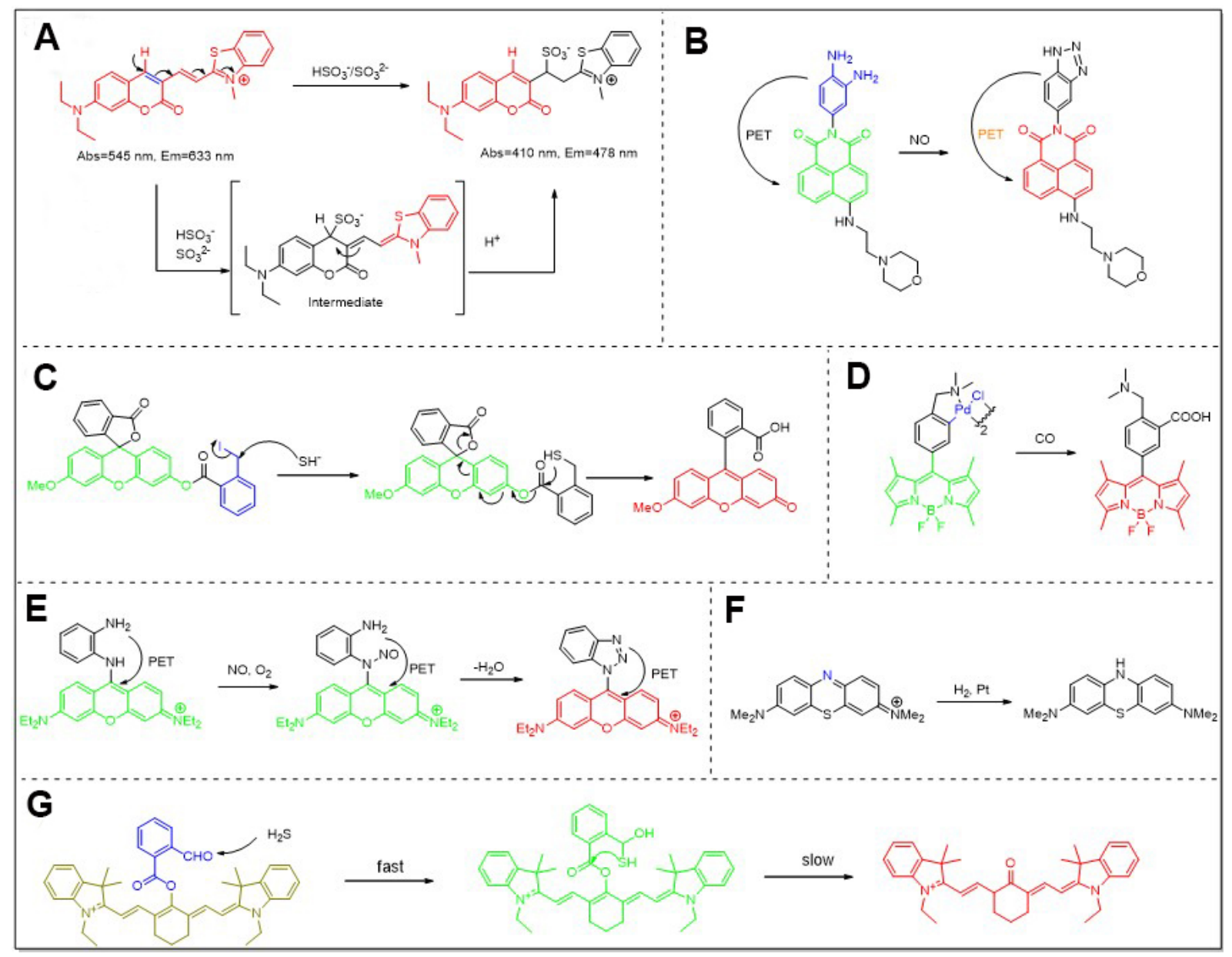

Figure 3. Typical gas probes and their detection mechanisms. (A) Coumarin-based probe for $\mathrm{SO}_{2}$ detection; (B) NDI-based probe for NO detection; (C) Rhodamine-based probe for $\mathrm{H}_{2} \mathrm{~S}$ detection; (D) BODIPY-based probe for $\mathrm{CO}$ detection; (E) Fluorescein-based probe for $\mathrm{NO}$ detection; (F) Methylene blue-based probe for $\mathrm{H}_{2}$ detection; (G) Cy7-based probe for $\mathrm{H}_{2} \mathrm{~S}$ detection.

Zheng et al. ${ }^{[23]}$.

Apart from the ring-opening and closing principle, another design concept is based on the introduction of a new recognition moiety [Figure 3E]. As early as 1998 , Kojima et al. ${ }^{[24]}$ reported the fluorescein-based NO probes whose NO detection was based on the reaction between $\mathrm{NO}$ and vicinal diamines. They introduced an aromatic structure containing two amine groups to the meso position of fluorescein. After the formation of a triazole with NO, fluorescence quantum efficiency increased by more than 100 times. Later, this diamines approach was further used in designing varied NO detection probes based on xanthene $\mathrm{e}^{[25-27]}$.

Another major design concept is based on the protection of hydroxyl group. Garner et al ${ }^{[28]}$ reported a fluorescent ozone probe based on fluorescein using butenyl as a protection group. The terminal olefin of the probe could react with $\mathrm{O}_{3}$ via cycloaddition, and the intermediate then decomposed to give an aldehyde which further underwent a $\beta$-elimination reaction. At last, the deprotected fluorescent species were formed with the production of acrylaldehyde. Compared to previously reported probes, the selectivity of the xanthene-based ozone probe is much better, and the product is fluorescent so the reaction is visualized easily. Levulinate, as mentioned above, is another protection moiety and readily reacted with $\mathrm{H}_{2} \mathrm{~S}$. Following a similar concept, other fluorescent probes based on xanthene were built for the detection of $\mathrm{H}_{2}{ }^{[29,30]}$ and 
A
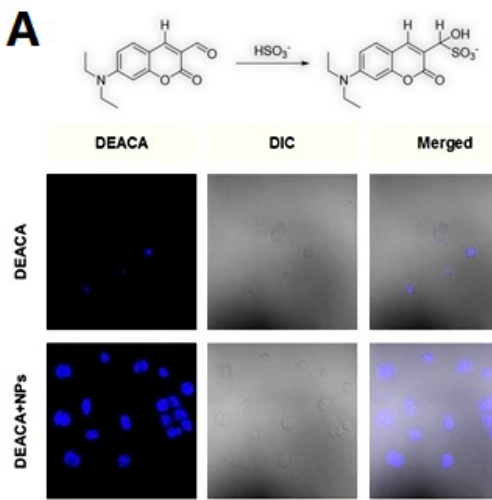

D

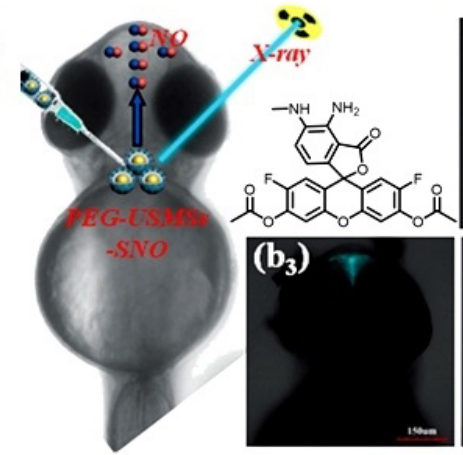

$\left(b_{1}\right)$
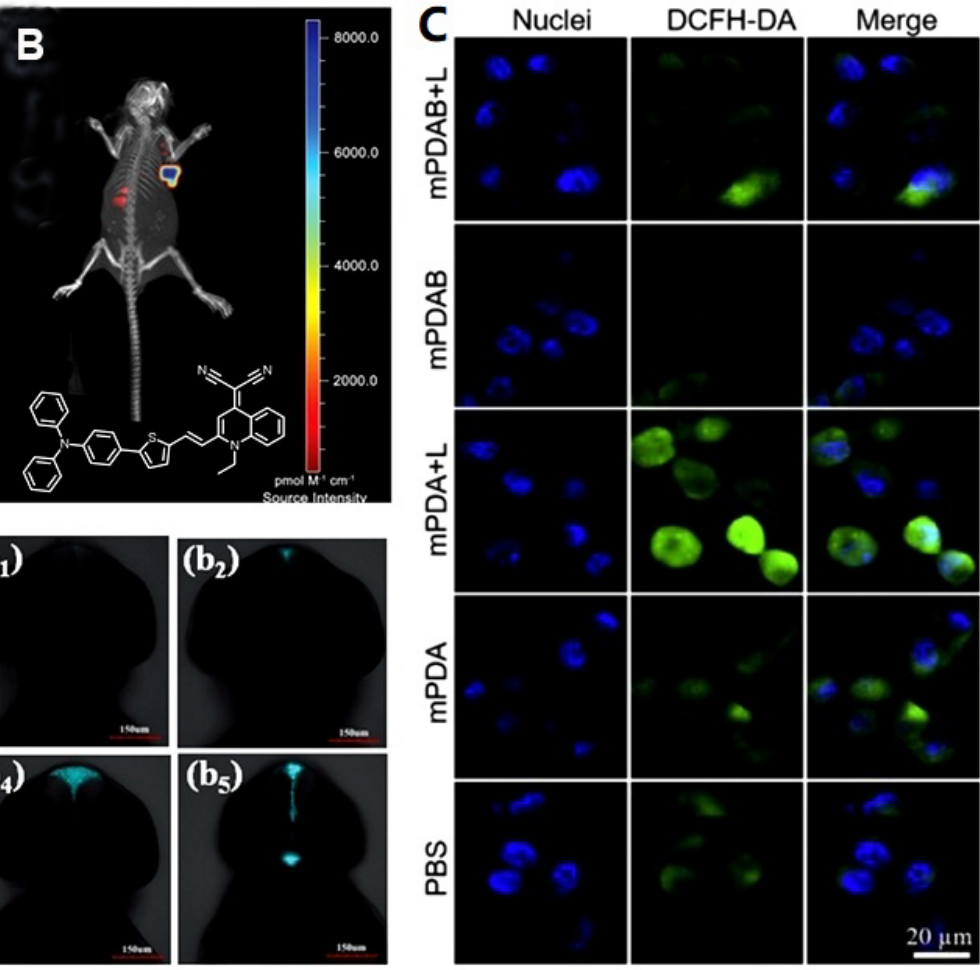

E
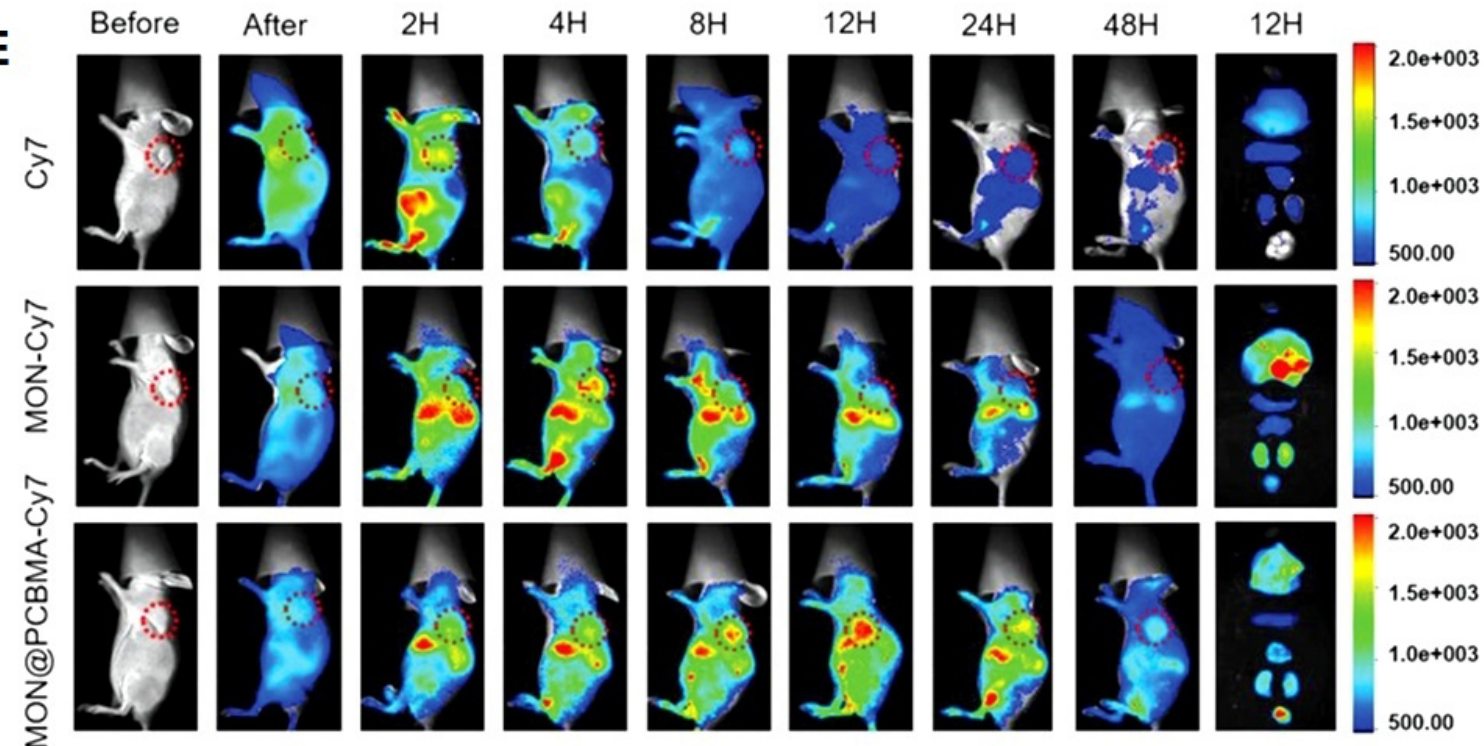

Figure 4. Applications of probes in gas therapy: $(A)$ coumarin-based probe (DEACA) for $\mathrm{SO}_{2}$ detection ${ }^{[9]}$; (B) $\mathrm{QM}-2$ for imaging drug distribution and accumulation in vivo ${ }^{[49]}$; (C) DCFH-DA for ROS evaluation in hydron therapy ${ }^{[25]}$; (D) DAF-FM DA for NO detection ${ }^{[59] \text {; }}$ (E) Cy7 for imaging drug distribution and accumulation in vivo ${ }^{[48]}$.

$\mathrm{CO}^{[31,32]}$.

\section{Cyanine-based gas probes}

With increasing requirements of fluorescence imaging, common fluorophores that emit photons in the ultraviolet/blue spectral range window are not suitable for deep tissue imaging. Thus, the fluorophores 
which could emit fluorescence in the NIR window are more attractive. Though common fluorophores could be modified to expand their conjunction system, their synthesis is complicated and the products are fragile. Cyanine, a commonly used fluorophore, could be relatively easily prepared. The photophysical properties rely on its methene group number, and thus the emission wavelength could be effortlessly tuned to NIR, which makes cyanine dyes suitable for bioimaging and protein-labeling.

Wang et al. ${ }^{[33]}$ reported a tandem nucleophilic addition/cyclization reaction-based $\mathrm{H}_{2} \mathrm{~S}$ detection probe, HSCy [Figure $3 \mathrm{G}$ ]. Heptamethine dyes and 2-carboxybenzaldehyde were chosen as cyanine core and $\mathrm{H}_{2} \mathrm{~S}$ detection units, respectively. Because only hydroxy-cyanine underwent tautomerism and stayed in the ketone form under a physiological $\mathrm{pH}$ value of 7.4, an ester bond rather than a more common ether bond was chosen as a linker. As a result, in the presence of analyte, $\mathrm{H}_{2} \mathrm{~S}$ attacked aldehyde firstly, then the formed sulfhydryl group attacked the ester linkage, and at last, hydroxyl cyanine which was produced by the cleavage of ester link was transferred into its keto form. Compared to the reactant, the emission intensity of the product at $780 \mathrm{~nm}$ excited at $700 \mathrm{~nm}$ decreased, while the emission intensity at $625 \mathrm{~nm}$ excited at 510 $\mathrm{nm}$ increased. And these ratiometric signal changes were adopted to monitor the endogenously generated $\mathrm{H}_{2} \mathrm{~S}$ in human A549 cells.

Another $\mathrm{H}_{2} \mathrm{~S}$ detection probe based on cyanine was reported by Yu et al. ${ }^{[34]}$. Different from Wang et al..$^{[33]}$ 's strategy, an internal charge transfer modulating method was adopted for probe designing. It is widely known that functional groups with different electron-donating abilities adjacent to fluorophore would result in internal charge transfer-induced blue or red shifts of its fluorescence spectrum. Thus, $\mathrm{N}_{3}$ as an electronwithdrawing moiety was attached to the meso position of cyanine. In the presence of $\mathrm{H}_{2} \mathrm{~S}$, the azido group would be reduced to an electron-donating $\mathrm{NH}_{2}$. As a consequence, a colorimetric and ratiometric fluorescent probe was achieved and was available for intracellular $\mathrm{H}_{2} \mathrm{~S}$ detection.

\section{Polycyclic aromatic hydrocarbons-based gas probes}

Polycyclic aromatic hydrocarbons (PAHs) are a class of compounds composed of multiple aromatic rings. Owing to their special structure, PAHs are usually very stable, which allowed them to become the most widespread organic contaminants in the aquatic environment ${ }^{[35]}$. But as to fluorescent probes, their high photostability, chemical resistance, and intrinsic fluorescence properties in the ultraviolet/blue spectral range turn their candidatures.

Naphthalene, the simplest PAH, is not suitable to be used for constructing fluorescent probes because of its short emission wavelength. Another obstacle against its further bioimaging application is its poor solubility. It is very hard to overcome these shortcomings by direct modification of the core structure of naphthalene, but one of its derivatives can solve those problems. The substitution product of naphthalic anhydride gives to the naphthalimide which absorbs and emits light in the visible range. Moreover, photophysical properties and solubility could be further tuned by modification with different functional groups. Thus, compared to naked naphthalene, naphthalimide is more suitable for fluorescent probe construction ${ }^{[36]}$. Yu et al. ${ }^{[37]}$ designed and synthesized a naphthalimide-based NO probe. Similar to the previously mentioned NO detection method, an aromatic diamine moiety was directly linked to the fluorophore and a lysosome targeting moiety was further attached to another site [Figure 3B]. After reaction with NO, the photoinduced electron transfer between aromatic diamine and naphthalene was interrupted, resulting in obvious fluorescence enhancement. With this molecule, NO within lysosomes of macrophage cells was captured and detected fluorescently. 
Other PAHs such as fluorene, anthracene, pyrene, and perylene can also be designed for fluorescent probes $^{[38-40]}$. But with the amount of aromatic cycle increased, the aqueous solubility of probes decreased heavily and the $\pi-\pi$ stacking between them increased, leading to fluorescence quenching. However, the excimer formed during the $\pi-\pi$ stacking is another strategy for probe design, but there is no relative report as far.

\section{APPLICATIONS OF GAS PROBES IN GAS THERAPY}

As discussed above, the therapeutic gases may turn to be toxic, hazardous, or poisonous at a relatively high concentration. Thus, it is meaningful and necessary to monitor gas concentration during therapy. On the other hand, though traditional gas administration methods including direct gas inhalation or drinking gasrich water are widely accepted, the potential risk induced by overdose should be carefully considered. Moreover, it is hard to precisely control the penetration and distribution of gases by these approaches. To overcome these problems, numerous nanomedicines have been developed for gas delivery. Compared to traditional gas delivery methods, nanomedicines are more intelligent with augmenting cancer therapy effects and lowering side effects. However, nanomedicine is an indirect gas supplying method. So gas therapy based on nanomedicines would typically go through three processes: nanomedicine delivery, gas release, and therapy. It is not complicated to design a nanomedicine with gas delivery ability, but how to optimize the delivery efficiency, release efficiency, and therapeutic effect requires much more endeavor. Fluorescent probes could participate in the whole gas therapy process and visualize the nanomedicine transportation, distribution, and enrichment. Moreover, with certain sensors, the gas releasing process and efficiency and even therapy effects could also be visualized by fluorescent imaging. Thus, in this section, the applications of fluorescent probes in the gas therapy field [Table 2] will be discussed.

\section{Gas probes for gas delivery evaluation}

Gas delivery is the first and most important step for gas therapy. Without a carefully designed carrier, therapeutic gas molecules could not be efficiently delivered to the targeting tissue and possibly caused toxic side effects. By encapsulating fluorophores or taking fluorescent molecules as a building block for constructing the gas-releasing nanomedicine, fluorescence imaging could be used to monitor the transportation of gases. As illustrated and synthesized by Meng et al. ${ }^{[41]}$, the delivery process of nanomedicine may undergo three stages: tumor, cell, and organelle. During the first stage, nanomedicines injected into the mice would stay in the blood for a while and then be enriched in different organisms depending on their structure ${ }^{[4]}$. In this research, the carrier MSN (mesoporous silica nanoparticle) was labeled with RITC which is a commonly used fluorescence dye with a stable structure and good water solubility. And another fluorescent molecule QL was attached onto FeCO-TPP to distinguish the different delivery behaviors. With the help of fluorescence imaging, they found that the FeCO-TPP@MSN@HA nanomedicine could be efficiently accumulated into the tumor by the EPR effect. But the emission maximum of RITC is around $600 \mathrm{~nm}$ which is not sufficient for deep tissue imaging. The same problem also exists in the case of $\mathrm{TPy}^{[42]}$, $\mathrm{DOX}^{[43]}$, and $\mathrm{Cy}^{\left[{ }^{[4]}\right]}$. To circumvent this problem, NIR fluorophores such as Cy5. $5^{[45,46]}, \mathrm{DPP}^{[47]}, \mathrm{Cy}^{[48]}\left[\right.$ Figure 4E], and $\mathrm{QM}-2^{[49]}$ [Figure $4 \mathrm{~B}$ ] are preferred to perform the in vivo delivery visualization.

After accumulation in the tumor site, the next important step is cell uptake. Generally, materials transported in and out of cells could be divided into two ways which are passive and active cell transport. In most cases of nanomedicine delivery, the size of carrier is too large to go through the plasma membrane passively. Thus, they can only cross the plasma membrane with a different sort of help, called vesicle transport. This process requires extra energy so not all nanoparticles could go into cells and cellular uptake efficiency is varied in different materials. Therefore, it is necessary to evaluate the cell uptake efficiency before its 
Table 2. Probes used in gas therapy

\begin{tabular}{|c|c|c|c|c|}
\hline \multicolumn{2}{|l|}{ Application } & \multirow{2}{*}{$\begin{array}{l}\text { Probe } \\
\text { RITC }\end{array}$} & \multirow{2}{*}{$\begin{array}{l}\text { Usage } \\
\text { Cell uptakes }\end{array}$} & \multirow{2}{*}{$\frac{\text { Ref. }}{[50-52]}$} \\
\hline Gas delivery evaluation & In vitro & & & \\
\hline & & FITC & Cell uptakes & {$[44,45,53]$} \\
\hline & & Cy7 & Cell uptakes & [13] \\
\hline & & UCNPs & Cell uptakes & {$[10]$} \\
\hline & & UCNPS & Intracellular delivery & {$[10]$} \\
\hline & & DOX & Cell uptakes & {$[9,56]$} \\
\hline & & RITC & Intracellular delivery & {$[41]$} \\
\hline & & QM-2 & Cell uptakes & [49] \\
\hline & & Nile Blue & Cell uptakes & {$[55]$} \\
\hline & & Cу3 & Cell uptakes & {$[54]$} \\
\hline & & NDI & Intracellular delivery & {$[57]$} \\
\hline & & Itself & Intracellular delivery & {$[70]$} \\
\hline & In vivo & Cy7 & Accumulation & {$[48]$} \\
\hline & & Ru-Complex & Accumulation & {$[60]$} \\
\hline & & Cy7 & Biodistribution & {$[48,54]$} \\
\hline & & Трур & Biodistribution & {$[42]$} \\
\hline & & DPP & Accumulation & {$[47]$} \\
\hline & & RITC & Accumulation & [41] \\
\hline & & QM-2 & Biodistribution & [49] \\
\hline & & RITC & Biodistribution & [51] \\
\hline & & DOX & Biodistribution & {$[43]$} \\
\hline & & Cy5 & Biodistribution & {$[44]$} \\
\hline & & Cy5.5 & Biodistribution & {$[45,46]$} \\
\hline \multirow[t]{13}{*}{ Gas release evaluation } & Solution & DEACA & $\mathrm{SO}_{2}$ release & {$[9,10,48]$} \\
\hline & & Hemoglobin & CO release & {$[13,46,51,55,72-74]$} \\
\hline & & $\mathrm{MB}$ & $\mathrm{H}_{2}$ release & {$[42]$} \\
\hline & & Griess reagent & NO release & {$[43,49,53,56,59,64,65,70]$} \\
\hline & & DAF-FM DA & NO release & {$[47]$} \\
\hline & Cell & COP-1 & CO release & {$[13,41,51,72,73]$} \\
\hline & & DAF-DA & NO release & {$[43]$} \\
\hline & & $\mathrm{FI}-\mathrm{CO}-1$ & CO release & {$[46]$} \\
\hline & & $\mathrm{MB}$ & $\mathrm{H}_{2}$ release & {$[52]$} \\
\hline & & DEACA & $\mathrm{SO}_{2}$ release & [9] \\
\hline & & DAF-FM DA & NO release & {$[47,49,56,57,59-63]$} \\
\hline & & RhBS & NO release & {$[64-66]$} \\
\hline & Fish & DAF-FM DA & NO release & [59] \\
\hline \multirow[t]{8}{*}{ Gas therapy evaluation } & Cell & DCFH-DA & ROS & {$[9,10,13,45-48,52,53,57,59,68]$} \\
\hline & & H\&E & Cell apoptosis & {$[10,45,48,53,56,57,59,60,63,70,71]$} \\
\hline & & L-012 & Inflammation & {$[45,67]$} \\
\hline & & HPF & $\mathrm{OH}$ & {$[75]$} \\
\hline & & Methylene blue & $\mathrm{OH}$ & [59] \\
\hline & & MitoTracker Red & Mitochondrial damage & {$[50]$} \\
\hline & Mice & L-012 & ROS & {$[45]$} \\
\hline & & DHE & ROS & [13] \\
\hline
\end{tabular}

application in therapy. Because this assessment could be done at the cellular level, common fluorophores such as RITC ${ }^{[50-52]}$, FITC ${ }^{[44,45,53]}$, Cy3 $3^{[54]}$, Cy $7^{[13]}$, QM-2 ${ }^{[49]}$, Nile blue ${ }^{[55]}$, and even DOX ${ }^{[9,56]}$ could be competent. But these fluorophores usually do not contribute to gas delivery and adding these indicators to the platform 
is time costly. A more convenient way to achieve the same performance is that the materials used for construction are of fluorescence themselves. Li et al. ${ }^{[10]}$ built a NIR-triggered $\mathrm{SO}_{2}$-releasing nanoparticle with a UNCP core consisted of $\mathrm{NaYF}_{4}$ and TIM/Yb. The UNCP could not only convert NIR light to UV light to trigger $\mathrm{SO}_{2}$ release but its green fluorescence can also be used for cellular uptake monitoring.

In fact, for the majority of gas delivery systems, it is sufficient to ship prodrugs to the tumor site. Because after gas release, gas molecules could diffuse into cells to play their therapeutic roles. Though this diffusion method is more efficient for membrane crossing, a considerable part of therapeutic gas is wasted since its diffusion is aimless. More importantly, the organelle-targeted gas delivery will undoubtedly have a better therapeutic effect and minimal side effects. And the commonly used method to determine which organelle is targeted is based on fluorescence microscopy technology called colocalization. The colocalization is carried out at the cellular level so the choice of fluorophores is simple. Only one rule should be taken into consideration and that is that the fluorophore chosen should have a separate emission wavelength from the commercial targeting probes. For example, the relationship between lysosomal dysfunction and programmed cell death has been evidenced. To enhance the therapeutic effect of NO gas, a lysosometargeted prodrug was developed by Xiang et al. ${ }^{[57]}$. To improve its targeting performance, folic acid was chosen to guide the nanomedicine to cancer cells and the morpholine moiety in the structure could further lead prodrugs targeting lysosome after entering cells. Moreover, due to the naphthalimide moiety in the structure, the nanoplatform exhibited a fluorescence emission, which was taken for tracing the delivery process. By comparison with the blue fluorescence of Lyso-Ru-NO@FA@C-TiO and the red fluorescence of commercial lyso-tracer, nanoparticles were confirmed to be transported to the lysosome in a targeted way.

\section{Gas probes for gas release evaluation}

The first step to realize gas therapy by nanomedicines is to transport them into the tumor site, but the core concept of this system is to release therapeutic gases. Moreover, it is critical to ensure the concentration of medical gas stays in a safety window, and gas releasing rates should also be taken into consideration. Releasing too fast would increase the concentration in a relatively short time and the therapeutic effect is possibly not sustainable. Thus, it is of significant meaning to value the releasing behaviors before clinic application.

As discussed in Section 2, chemists have developed a large number of optical probes for gas detection with different mechanisms. A part of them have been used to assess the gas releasing performance in gas therapy. For example, the feasibility of gas therapy research should be assessed at the beginning, and most of them are done in solution. Thus, it is very convenient to obtain the rate, amount and conditions of gas release. Hydrogen gas, for example, is very stable in physical conditions and can be hardly trapped by other molecules in a normal situation. So in gas therapy research related to hydrogen ${ }^{[42]}$, the methylene blue (MB) method $^{[58]}$ was adopted to measure hydrogen gas produced by nanomedicines [Figure $3 \mathrm{~F}$ ]. Due to the inert property of $\mathrm{H}_{2}$, the blue color of $\mathrm{MB}$ can be quickly reduced in the presence of $\mathrm{Pt}$ as a catalyst. Since the reaction ratio of $\mathrm{MB}$ to $\mathrm{H}_{2}$ is 1:1 and the concentration of $\mathrm{MB}$ is proportional to its UV absorbance value, the $\mathrm{H}_{2}$ releasing properties in different conditions were quantitively obtained and it was found that the developed MBN (magnesium boride nanosheet) nanomedicine was stable in physical condition but rapidly release $\mathrm{H}_{2}$ in an acid solution which was preferred in gastric cancer. Other gas detection methods based on UV spectrometers include the use of hemoglobin for detecting CO gas due to its high affinity towards CO, and sulfanilamide - N-1-napthylethylenediamine dihydrochloride based Griess reagent for NO detection. The reaction between Griess reagent and NO-derived nitrosating agent contained two steps: first, sulfanilamide reacted with $\mathrm{NO}$ oxidation product to give a diazonium ion, and then a chromophoric azo compound was formed by the coupling reaction between diazonium ion and $\mathrm{N}$-(1- 
napthyl)ethylenediamine.

Though detection methods based on UV spectrometer are reliable, the sensitivity of UV is far inferior to that of fluorescence. Thus, fluorescent probes for gases and fluorescent detection technologies based on them are more applicable in gas therapy. As mentioned above, the coumarin-based fluorescent probe DEACA is sensitive to $\mathrm{SO}_{2}$ so it has been widely used to detect $\mathrm{SO}_{2}$ in related researches ${ }^{[9,10,48]}$. These phenomena could also be observed in other fluorescent probes. Both COP-1 and Fl-CO-1 are designed for the detection of CO. Compared to Fl-CO-1, the emission wavelength of COP-1 is shorter, but COP- 1 can accomplish the whole detection without additional materials like $\mathrm{PdCl}_{2}$ which was used in the case of FlCO-1. Also, DAF-FM DA ${ }^{[49,47,56,57,59-63]}$ [Figure 4D], DAF-DA ${ }^{[43]}$ and RhBS ${ }^{[64-66]}$ are used for NO detection, and the difference between them is similar to that between fluorescein and rhodamine. It is reasonable to choose any one of them for gas detection. With diacetate moiety, DAF-FM DA and DAF-DA own better cell penetration ability so it is more widely used ${ }^{[59]}$ at the cell level. However, owing to having two fluorine atoms in the structure, DAF-FM DA is more photostable and sensitive compared to DAF-DA.

\section{Gas probes for gas therapy evaluation}

Successful gas delivery and release do not equal to effective treatment. The gas-induced therapeutic effect may go through three stages: first, gases released in cells could affect the regular metabolism such as ROS generation and $\cdot \mathrm{OH}$ elimination, later, the broken balance may further influence normal functions of organelles, and last leads to the cell apoptosis. These different stages could be determined by suitable fluorescent probes in varied gas therapy researches.

As known to all, because of high reactivity, ROS is widely regarded as an etiologic factor for diseases like inflammation, and the scavenging of ROS may reduce cell damage. Thus, gas therapy based on this concept needs to evaluate the ROS level to judge its therapeutic effect. In the research related to hydrogen gas therapy ${ }^{[67]}$, a fluorescein-based probe DCF-DA/DCFH-DA was used to quantify ROS level. This probe is non-fluorescent and could penetrate the cell membrane easily. After uptake by cells, the diacetates were hydrolyzed to give DCFH. With high oxidizing ability, ROS in cells would oxidize DCFH to DCF which could be monitored by fluorescence technique. By this probe, the ROS level peak was determined at $6 \mathrm{~h}$, and based on this value, the proper pre-treated cells were used for the later experiment. Due to its excellent performance, DCHF-DA has been widely used for ROS evaluation at the cellular level ${ }^{[9,10,13,45-48,52,53,5,5,59,68]}$ [Figure $4 \mathrm{C}$ ]. But there are also some concerns that detection procedure could be influenced by $\mathrm{pH}$ value, reagent concentration, and extraction methods significantly ${ }^{[6]]}$. Moreover, the photo-reduced production of DCF is a semiquinone radical which in turn can produce ROS. This ROS-generating behavior may destroy the treatment. Thus, a luminol-based fluorescent probe, L-012, was developed and utilized in ROS detection at the animal level. In a recent research ${ }^{[45]}$, L-012 was injected into tumor and intratumoral ROS level during therapy was visualized by IVIS. By comparing with the control group, ROS level was significantly reduced in the presence of hydrogen gas, meaning that hydrogen gas could improve photothermal therapy and restrain the relapse of distant dormant tumors.

In some cases, gas molecules would directly target organelles and regulate their biological functions. So, to evaluate the therapeutic effects of gas molecules, a special targeting fluorescent probe is required. For example, hydrogen gas is regarded to target the mitochondria, and the regulation influence varies from normal and cancer cells. To investigate the selective anti-cancer mechanism, the commercial mitochondria targeting probe, MitoTracker Red CMXRos, was used to value the mitochondria damage. MitoTracker Red CMXRos is a rhodamine-based fluorophore that could attach mitochondria by membrane potential. So, if the mitochondria are damaged or dysfunctional, the interaction between them and probes is weakened, 
leading to a less accumulation of fluorescent probes. Based on this principle, the different impact of hydrogen gas on mitochondria was illustrated.

In the third stage of therapy, cancer cells should be killed by gas molecules directly or indirectly, and this effect could be easily evaluated by a proven solution called Annexin V Apoptosis Assay. The Annexin V Apoptosis Assay commonly containing two fluorophores which are Annexin V conjugated FITC and propidium iodide. In normal cells, the phosphatidylserine is located in the inner side of the membrane and upon apoptosis, the structure of phospholipids is disrupted, making the phosphatidylserine exposed to Annexin V which owns a high affinity to phosphatidylserine. Thus, by Annexin V Apoptosis Assay, dead and normal cells could be easily separated by different colors using fluorescence techniques. And in gas therapy, therapeutic gas molecules induced cell death, or its enhancement effect on other therapies such as chemotherapy and radiotherapy could be easily visualized $\mathrm{d}^{[10,45,48,53,5,5,57,59,60,63,70,71]}$.

\section{CONCLUSION AND OUTLOOK}

In this review, the use of fluorescent probes in the detection of therapeutic gases and their applications in gas therapy were summarized and discussed. Special attention was given to the gas detection mechanisms, and indicators based on these mechanisms for gas delivery, release, and assessment of therapeutic effects. Several Vis/NIR probes have been designed to monitor $\mathrm{H}_{2} \mathrm{~S}$ concentration in solution and cells. However, these probes are rarely applied in vivo especially in the field of gas therapy. It is a great challenge to overcome the penetration and autofluorescence problems when using fluorescent probes. And at this point, photoacoustic probes may be a better choice. As for other gases, numerous fluorophores ranging from Vis to NIR have been developed. And some of them such as COP-1 for CO, DAF-FM DA for NO, and MB for $\mathrm{H}_{2}$ have even become commercial.

However, in comparison with the history of fluorescence, gas therapy is just like a newborn baby. As time goes by, fluorophores and their related technologies have become a universal tool for various basic research and clinical applications. But advanced fluorescent imaging technologies such as three-dimensional imaging and super-resolution imaging have seldom been used for gas therapy.

Many problems are awaiting a solution in the gas therapy field, such as how gases penetrate biomembranes, what their rates are, and what the target molecule/protein of gases are. For these problems, fluorophorebased fluorescence imaging would be a powerful tool to help researchers to solve the problem or assist them in improving the therapeutic effect of gases. As mentioned above, the distribution of nanomedicine could be visualized by IVIS imaging, so with these probes, tumor size could be calculated by three-dimensional imaging. Compared to the rough calculation of tumor volume, using imaging technology is undoubtedly more accurate and straightforward. But the long-time scanning requires extra stability of probe and its resistance to the complicated cellular environment.

On the other hand, the interaction between gas and protein is usually beyond the imaging capacity of normal confocal fluorescence microscopy. But super-resolution microscopy (SRM) including near-field optical random mapping microscopy, structured illumination microscopy, stimulated emission depletion, and stochastic optical reconstruction microscopy could offer living imaging with higher resolution at the sub-cellular level. With these technologies, researchers could probably observe the targeting site of gases and analyze the interaction processes. However, it is difficult to develop fluorophores suitable for SRM, and adding gas detection function to fluorophores requires more complicated design. 
Therefore, given the desirable properties of fluorophores and the continued development of imaging technologies, the development of related gas probes is of great importance for improvement of gas therapy as well as for better understanding of the roles of gases in living systems.

\section{DECLARATIONS}

\section{Authors' contributions}

Collected and analyzed relevant literatures, and wrote the draft and designed figures: Gong WJ

Participated in the analysis and organization of the literature and modified the draft: Yu ZQ

The conceptualizer and leader of the project and directed the writing and modified the manuscript: He QJ

\section{Availability of data and materials}

Not applicable.

\section{Financial support and sponsorship}

This work was supported by the National Natural Science Foundation of China (51872188), Special Funds for the Development of Strategic Emerging Industries in Shenzhen (20180309154519685), SZU Top Ranking Project (860-00000210), and Center of Hydrogen Science, Shanghai Jiao Tong University, China.

\section{Conflicts of interest}

All authors declared that there are no conflicts of interest.

\section{Ethical approval and consent to participate}

Not applicable.

\section{Consent for publication}

Not applicable.

\section{Copyright}

(c) The Author(s) 2021.

\section{REFERENCES}

1. Chen K, Guo Y, Lu Z, Yang B, Shi Z. Novel coumarin-based fluorescent probe for selective detection of bisulfite anion in water. Chin J Chem 2010;28:55-60. DOI

2. Li W, Sun W, Yu X, Du L, Li M. Coumarin-based fluorescent probes for $\mathrm{H}_{2} \mathrm{~S}$ detection. J Fluoresc 2013;23:181-6. DOI PubMed

3. Yang Y, Huo F, Zhang J, et al. A novel coumarin-based fluorescent probe for selective detection of bissulfite anions in water and sugar samples. Sens Actuators B Chem: Chemical 2012;166-167:665-70. DOI

4. Wu MY, He T, Li K, Wu MB, Huang Z, Yu XQ. A real-time colorimetric and ratiometric fluorescent probe for sulfite. Analyst 2013;138:3018-25. DOI PubMed

5. Wu MY, Li K, Li CY, Hou JT, Yu XQ. A water-soluble near-infrared probe for colorimetric and ratiometric sensing of $\mathrm{SO}_{2}$ derivatives in living cells. Chem Commun (Camb) 2014;50:183-5. DOI PubMed

6. Sun YQ, Liu J, Zhang J, Yang T, Guo W. Fluorescent probe for biological gas $\mathrm{SO}_{2}$ derivatives bisulfite and sulfite. Chem Commun (Camb) 2013;49:2637-9. DOI PubMed

7. Liu Z, Guo S, Piao J, Zhou X, Wu X. A reversible fluorescent probe for circulatory detection of sulfites through a redox-based tandem reaction. RSC Adv 2014;4:54554-7. DOI

8. Hatai J, Hirschhäuser C, Schmuck C, Niemeyer J. A metallosupramolecular coordination polymer for the "Turn-on" fluorescence detection of hydrogen sulfide. ChemistryOpen 2020;9:786-92. DOI PubMed PMC

9. Shen W, Liu W, Yang H, Zhang P, Xiao C, Chen X. A glutathione-responsive sulfur dioxide polymer prodrug as a nanocarrier for combating drug-resistance in cancer chemotherapy. Biomaterials 2018;178:706-19. DOI PubMed

10. Li S, Liu R, Jiang X, et al. Near-infrared light-triggered sulfur dioxide gas therapy of cancer. ACS Nano 2019;13:2103-13. DOI PubMed

11. Michel BW, Lippert AR, Chang CJ. A reaction-based fluorescent probe for selective imaging of carbon monoxide in living cells using a palladium-mediated carbonylation. J Am Chem Soc 2012;134:15668-71. DOI PubMed

12. Jin Z, Wen Y, Xiong L, et al. Intratumoral $\mathrm{H}_{2} \mathrm{O}_{2}$-triggered release of $\mathrm{CO}$ from a metal carbonyl-based nanomedicine for efficient $\mathrm{CO}$ therapy. Chem Commun (Camb) 2017;53:5557-60. DOI PubMed 
13. Yao X, Yang P, Jin Z, et al. Multifunctional nanoplatform for photoacoustic imaging-guided combined therapy enhanced by CO induced ferroptosis. Biomaterials 2019;197:268-83. DOI PubMed

14. Bartelmess J, Valderrey V, Rurack K. Development of a "Turn-on" fluorescent probe-based sensing system for hydrogen sulfide in liquid and gas phase. Front Chem 2019;7:641. DOI PubMed PMC

15. Gu X, Liu C, Zhu YC, Zhu YZ. A boron-dipyrromethene-based fluorescent probe for colorimetric and ratiometric detection of sulfite. J Agric Food Chem 2011;59:11935-9. DOI PubMed

16. Gabe Y, Urano Y, Kikuchi K, Kojima H, Nagano T. Highly sensitive fluorescence probes for nitric oxide based on boron dipyrromethene chromophore-rational design of potentially useful bioimaging fluorescence probe. J Am Chem Soc 2004;126:3357-67. DOI PubMed

17. Paul N, Sarkar R, Sarkar R, Barui A, Sarkar S. Detection of hydrogen sulfide using BODIPY based colorimetric and fluorescent on-off chemosensor. J Chem Sci 2020:132. DOI

18. Qian Y, Karpus J, Kabil O, et al. Selective fluorescent probes for live-cell monitoring of sulphide. Nat Commun 2011;2:495. DOI PubMed

19. Schutting S, Jokic T, Strobl M, Borisov SM, Beer DD, Klimant I. NIR optical carbon dioxide sensors based on highly photostable dihydroxy-aza-BODIPY dyes. J Mater Chem C 2015;3:5474-83. DOI

20. Noelting E, Dziewoński K. Zur kenntniss der rhodamine. Ber Dtsch Chem Ges 1905;38:3516-27. DOI

21. Baeyer A. Ueber eine neue klasse von farbstoffen. Ber Dtsch Chem Ges 1871;4:555-8. DOI

22. Zheng H, Shang GQ, Yang SY, Gao X, Xu JG. Fluorogenic and chromogenic rhodamine spirolactam based probe for nitric oxide by spiro ring opening reaction. Org Lett 2008;10:2357-60. DOI PubMed

23. Zhang J, Sun YQ, Liu J, Shi Y, Guo W. A fluorescent probe for the biological signaling molecule $\mathrm{H}_{2} \mathrm{~S}$ based on a specific $\mathrm{H}_{2} \mathrm{~S}$ trap group. Chem Commun (Camb) 2013;49:11305-7. DOI PubMed

24. Kojima H, Nakatsubo N, Kikuchi K, et al. Detection and imaging of nitric oxide with novel fluorescent indicators: diaminofluoresceins. Anal Chem 1998;70:2446-53. DOI PubMed

25. Kojima H, Nagano T. Fluorescent indicators for nitric oxide. Adv Mater 2000;12:763-5. DOI

26. Sun YQ, Liu J, Zhang H, et al. A mitochondria-targetable fluorescent probe for dual-channel NO imaging assisted by intracellular cysteine and glutathione. J Am Chem Soc 2014;136:12520-3. DOI PubMed

27. Kojima H, Hirotani M, Nakatsubo N, et al. Bioimaging of nitric oxide with fluorescent indicators based on the rhodamine chromophore. Anal Chem 2001;73:1967-73. DOI PubMed

28. Garner AL, St Croix CM, Pitt BR, Leikauf GD, Ando S, Koide K. Specific fluorogenic probes for ozone in biological and atmospheric samples. Nat Chem 2009;1:316-21. DOI PubMed PMC

29. Choi MG, Hwang J, Eor S, Chang SK. Chromogenic and fluorogenic signaling of sulfite by selective deprotection of resorufin levulinate. Org Lett 2010;12:5624-7. DOI PubMed

30. Liu C, Pan J, Li S, et al. Capture and visualization of hydrogen sulfide by a fluorescent probe. Angew Chem Int Ed Engl 2011;50:10327-9. DOI PubMed PMC

31. Feng W, Liu D, Feng S, Feng G. Readily available fluorescent probe for carbon monoxide imaging in living cells. Anal Chem 2016;88:10648-53. DOI PubMed

32. Feng S, Liu D, Feng W, Feng G. Allyl fluorescein ethers as promising fluorescent probes for carbon monoxide imaging in living cells. Anal Chem 2017;89:3754-60. DOI PubMed

33. Wang X, Sun J, Zhang W, Ma X, Lv J, Tang B. A near-infrared ratiometric fluorescent probe for rapid and highly sensitive imaging of endogenous hydrogen sulfide in living cells. Chem Sci 2013;4:2551. DOI

34. Yu F, Li P, Song P, Wang B, Zhao J, Han K. An ICT-based strategy to a colorimetric and ratiometric fluorescence probe for hydrogen sulfide in living cells. Chem Commun (Camb) 2012;48:2852-4. DOI PubMed

35. Ferretto N, Tedetti M, Guigue C, Mounier S, Redon R, Goutx M. Identification and quantification of known polycyclic aromatic hydrocarbons and pesticides in complex mixtures using fluorescence excitation-emission matrices and parallel factor analysis. Chemosphere 2014;107:344-53. DOI PubMed

36. Montoya LA, Pluth MD. Selective turn-on fluorescent probes for imaging hydrogen sulfide in living cells. Chem Commun (Camb) 2012;48:4767-9. DOI PubMed PMC

37. Yu H, Xiao Y, Jin L. A lysosome-targetable and two-photon fluorescent probe for monitoring endogenous and exogenous nitric oxide in living cells. J Am Chem Soc 2012;134:17486-9. DOI PubMed

38. Hampe EM, Rudkevich DM. Reversible covalent chemistry of $\mathrm{CO}_{2}$. Chem Commun (Camb) 2002:1450-1. DOI PubMed

39. Dansby-Sparks RN, Jin J, Mechery SJ, et al. Fluorescent-dye-doped sol-gel sensor for highly sensitive carbon dioxide gas detection below atmospheric concentrations. Anal Chem 2010;82:593-600. DOI PubMed

40. Lee M, Moon JH, Swamy K, et al. A new bis-pyrene derivative as a selective colorimetric and fluorescent chemosensor for cyanide and fluoride and anion-activated $\mathrm{CO}_{2}$ sensing. Sensors and Actuators B: Chemical 2014;199:369-76. DOI

41. Meng J, Jin Z, Zhao P, Zhao B, Fan M, He Q. A multistage assembly/disassembly strategy for tumor-targeted CO delivery. Sci Adv 2020;6:eaba1362. DOI PubMed PMC

42. Fan $\mathrm{M}$, Wen $\mathrm{Y}$, Ye D, et al. Acid-responsive $\mathrm{H}_{2}$-releasing $2 \mathrm{D} \mathrm{MgB}_{2}$ nanosheet for therapeutic synergy and side effect attenuation of gastric cancer chemotherapy. Adv Healthc Mater 2019;8:e1900157. DOI PubMed

43. Guo R, Tian Y, Wang Y, Yang W. Near-infrared laser-triggered nitric oxide nanogenerators for the reversal of multidrug resistance in cancer. Adv Funct Mater 2017;27:1606398. DOI

44. Min KH, Min HS, Lee HJ, et al. pH-controlled gas-generating mineralized nanoparticles: a theranostic agent for ultrasound imaging 
and therapy of cancers. ACS Nano 2015;9:134-45. DOI PubMed PMC

45. Zhang C, Zheng DW, Li CX, et al. Hydrogen gas improves photothermal therapy of tumor and restrains the relapse of distant dormant tumor. Biomaterials 2019;223:119472. DOI PubMed

46. Zheng DW, Li B, Li CX, et al. Photocatalyzing $\mathrm{CO}_{2}$ to CO for enhanced cancer therapy. Adv Mater 2017;29:1703822. DOI PubMed

47. Wang Y, Huang X, Tang Y, et al. A light-induced nitric oxide controllable release nano-platform based on diketopyrrolopyrrole derivatives for pH-responsive photodynamic/photothermal synergistic cancer therapy. Chem Sci 2018;9:8103-9. DOI PubMed PMC

48. Yao X, Ma S, Peng S, et al. Zwitterionic polymer coating of sulfur dioxide-releasing nanosystem augments tumor accumulation and treatment efficacy. Adv Healthc Mater 2020;9:e1901582. DOI PubMed

49. Jia X, Zhang Y, Zou Y, et al. Dual intratumoral redox/enzyme-responsive no-releasing nanomedicine for the specific, high-efficacy, and low-toxic cancer therapy. Adv Mater 2018;30:e1704490. DOI PubMed

50. Kou Z, Zhao P, Wang Z, et al. Acid-responsive H2-releasing Fe nanoparticles for safe and effective cancer therapy. J Mater Chem B 2019;7:2759-65. DOI PubMed

51. Zhao B, Zhao P, Jin Z, Fan M, Meng J, He Q. Programmed ROS/CO-releasing nanomedicine for synergetic chemodynamic-gas therapy of cancer. $J$ Nanobiotechnology 2019;17:75. DOI PubMed PMC

52. Yang $\mathrm{T}$, Jin Z, Wang Z, et al. Intratumoral high-payload delivery and acid-responsive release of $\mathrm{H}_{2}$ for efficient cancer therapy using the ammonia borane-loaded mesoporous silica nanomedicine. Applied Materials Today 2018;11:136-43. DOI

53. Zhang K, Xu H, Jia X, et al. Ultrasound-triggered nitric oxide release platform based on energy transformation for targeted inhibition of pancreatic tumor. ACS Nano 2016;10:10816-28. DOI PubMed

54. Sun X, Kong B, Wang W, et al. Mesoporous silica nanoparticles for glutathione-triggered long-range and stable release of hydrogen sulfide. J Mater Chem B 2015;3:4451-7. DOI PubMed

55. der Vlies AJ, Inubushi R, Uyama H, Hasegawa U. Polymeric framboidal nanoparticles loaded with a carbon monoxide donor via phenylboronic acid-catechol complexation. Bioconjug Chem 2016;27:1500-8. DOI PubMed

56. Sun Z, Yi Z, Cui X, et al. Tumor-targeted and nitric oxide-generated nanogels of keratin and hyaluronan for enhanced cancer therapy. Nanoscale 2018;10:12109-22. DOI PubMed

57. Xiang HJ, Deng Q, An L, Guo M, Yang SP, Liu JG. Tumor cell specific and lysosome-targeted delivery of nitric oxide for enhanced photodynamic therapy triggered by $808 \mathrm{~nm}$ near-infrared light. Chem Commun (Camb) 2016;52:148-51. DOI PubMed

58. Seo T, Kurokawa R, Sato B. A convenient method for determining the concentration of hydrogen in water: use of methylene blue with colloidal platinum. Med Gas Res 2012;2:1. DOI PubMed PMC

59. Fan W, Bu W, Zhang Z, et al. X-ray Radiation-controlled NO-release for on-demand depth-independent hypoxic radiosensitization. Angew Chem Int Ed ;54:14026-30. DOI PubMed

60. Guo M, Xiang HJ, Wang Y, et al. Ruthenium nitrosyl functionalized graphene quantum dots as an efficient nanoplatform for NIRlight-controlled and mitochondria-targeted delivery of nitric oxide combined with photothermal therapy. Chem Commun (Camb) 2017;53:3253-6. DOI PubMed

61. Zhang X, Tian G, Yin W, et al. Controllable generation of nitric oxide by near-infrared-sensitized upconversion nanoparticles for tumor therapy. Adv Funct Mater 2015;25:3049-56. DOI

62. Lee HJ, Kim da E, Park DJ, et al. pH-Responsive mineralized nanoparticles as stable nanocarriers for intracellular nitric oxide delivery. Colloids Surf B Biointerfaces 2016;146:1-8. DOI PubMed

63. Zhang J, Song H, Ji S, et al. NO prodrug-conjugated, self-assembled, pH-responsive and galactose receptor targeted nanoparticles for co-delivery of nitric oxide and doxorubicin. Nanoscale 2018;10:4179-88. DOI PubMed

64. Fan J, He N, He Q, et al. A novel self-assembled sandwich nanomedicine for NIR-responsive release of NO. Nanoscale 2015;7:2005562. DOI PubMed PMC

65. Fan J, He Q, Liu Y, et al. Light-responsive biodegradable nanomedicine overcomes multidrug resistance via NO-enhanced chemosensitization. ACS Appl Mater Interfaces 2016;8:13804-11. DOI PubMed PMC

66. Fan W, Lu N, Huang P, et al. Glucose-responsive sequential generation of hydrogen peroxide and nitric oxide for synergistic cancer starving-like/gas therapy. Angew Chem Int Ed Engl 2017;56:1229-33. DOI PubMed

67. Wan WL, Lin YJ, Chen HL, et al. In situ nanoreactor for photosynthesizing $\mathrm{H}_{2}$ gas to mitigate oxidative stress in tissue inflammation. J Am Chem Soc 2017;139:12923-6. DOI PubMed

68. Wan WL, Lin YJ, Shih PC, et al. An in situ depot for continuous evolution of gaseous $\mathrm{H}_{2}$ mediated by a magnesium passivation/activation cycle for treating osteoarthritis. Angew Chem Int Ed Engl 2018;57:9875-9. DOI PubMed

69. Huang W, Zhang Y, Zhang Y, Fang D, Schauer JJ. Optimization of the measurement of particle-bound reactive oxygen species with 2',7'-dichlorofluorescin (DCFH). Water Air Soil Pollut 2016:227. DOI

70. Xu J, Zeng F, Wu H, Hu C, Yu C, Wu S. Preparation of a mitochondria-targeted and NO-releasing nanoplatform and its enhanced proapoptotic effect on cancer cells. Small 2014;10:3750-60. DOI PubMed

71. Xu Y, Ren H, Liu J, et al. A switchable NO-releasing nanomedicine for enhanced cancer therapy and inhibition of metastasis. Nanoscale 2019;11:5474-88. DOI PubMed

72. He Q, Kiesewetter DO, Qu Y, et al. NIR-responsive on-demand release of CO from metal carbonyl-caged graphene oxide nanomedicine. Adv Mater 2015;27:6741-6. DOI PubMed PMC

73. Fujita K, Tanaka Y, Abe S, Ueno T. A photoactive carbon-monoxide-releasing protein cage for dose-regulated delivery in living cells. Angew Chem Int Ed Engl 2016;55:1056-60. DOI PubMed

74. Li WP, Su CH, Tsao LC, Chang CT, Hsu YP, Yeh CS. Controllable CO release following near-infrared light-induced cleavage of iron carbonyl derivatized prussian blue nanoparticles for CO-assisted synergistic treatment. ACS Nano 2016;10:11027-36. DOI PubMed 
75. Kong L, Chen C, Mou F, et al. Magnesium particles coated with mesoporous nanoshells as sustainable therapeutic-hydrogen suppliers to scavenge continuously generated hydroxyl radicals in long term. Part Part Syst Charact 2019;36:1800424. DOI 